IRA-International Journal of Applied Sciences ISSN 2455-4499; Vol.04, Issue 01 (2016)

\title{
Study of Natural Radioactive Elements in The Environment of Bundelkhand Region
}

\author{
H. K. Garg, Rajiv Agrawal** \& Udita Garg* \\ **Research Lab. Chemistry Dept., D.B.S. College, Kanpur. (U.P.) India. \\ *Research Lab. Microbiology Dept., D.B.S. College, Kanpur. (U.P.) India. \\ Research Lab. Chemistry Dept., D.V. (P.G.) College, Orai. (U.P.) India.
}

DOI: http://dx.doi.org/10.21013/jas.v4.n1.p11

\section{How to cite this paper:}

Garg, H., Agrawal, R., \& Garg, U. (2016). Study of Natural Radioactive Elements in The Environment of Bundelkhand Region. IRA-International Journal of Applied Sciences (ISSN 2455-4499), 4(1). doi:http://dx.doi.org/10.21013/jas.v4.n1.p11

(C) Institute of Research Advances

\section{(cc) EY-NC}

This works is licensed under a Creative Commons Attribution-Non Commercial 4.0 International License subject to proper citation to the publication source of the work.

Disclaimer: The scholarly papers as reviewed and published by the Institute of Research Advances (IRA) are the views and opinions of their respective authors and are not the views or opinions of the IRA. The IRA disclaims of any harm or loss caused due to the published content to any party. 


\section{ABSTRACT}

Natural radioactive elements have been studied in the environment of some remote areas of Bundelkhand region. The nuclear radiations emitted were found as human health hazards by the applications of solid state nuclear track detector. Natural radioactive elements were mainly investigated as uranium and its radioactive products like radium and radon using nuclear technique such as laser flourimetry and $\gamma$-rays spectrometry radiation induced effect in the material were studied using heavy ion and irradiation facilities.

Key words- Radioactive elements, Uranium, Radon, Radium analysis, Heavy ion irradiation studies, laser flourimetry and $\gamma$-rays spectrometry radiation.

\section{INTRODUCTION:-}

The radioactive elements such as uranium, thorium and radon are found in traces in the earth's crust and found more or less uniformly through out the crust of Bundelkhand region. These elements emit radiations, which can be hazardous for human beings. Thus for environmental protection, the monitor of any release of radioactivity is essential for this region.

\section{EXPERIMENTAL RESULT AND DISCUSSION:-}

Natural radioactivity studies are necessary not only because of their radiological impact, but also because they acts as excellent biochemical and geo-chemical traces in the environment. Although the natural radioactivity is found in rocks and soils throughout the earth, the accession in Bundelkhand region varies relatively within narrow limits.

The heaviest radioactive toxic element, Uranium is found in all types of rocks and sandy soils, sand and water of different places. Uranium is soluble in aqueous solutions in the hexavalent form. The presence of excess amount of Uranium in drinking water and food stuffs may lead to very harmful effects in human beings. The radioactivity and some other chemical properties of Uranium are responsible for its adverse effects. Chemically Uranium and other natural radioactive elements can be harmful to the kidneys from large exposers. Uranium is ultimate source of Radium and Radon isotopes are the decay products of Radium in the Uranium disintegrated series. As an Inert gas Radon can diffuse through the soil and enter in the environment. It is well known (Henshaw et al; 1990) that indoor Radon exposure is associated with the leukemia and certain other cancerous diseases such as mylenoma and kidney cancer and prostate. If the Uranium rich material lies close to the surface of the earth, there can be high Radon exposure hazards (Seve et al. 1976; UNSCER, 2000).

The environmental radiations studies have achieved importance around world during recent years because of the serious health hazards effects of radiations and the solid state nuclear tracks detectors have played an important role in such investigations. These detectors have been employed by number of research groups in India and abroad for the analysis of the radioactive elements in the environmental samples and for the measurement of radiation levels in the mining and living places. A significant work has been carried out on Uranium, radium and Radon by number of investigations in India particularly in BARC, Mumbai using solid state nuclear track detectors and results are comparable with the established nuclear techniques such as Gamma Ray Spectrometry and Laser Flourimetry.

The solid state nuclear track detector group of this institution employed these detectors for four major studies.

1. Prospects of Uranium in the entire sixteen district of Bundelkhand region.

2. Correlation of Radon anomalies with seismic activities in some districts of this region.

3. Indoor Radon activities in the dwellings of some districts of this region.

4. Radiations damage studies in solids. 
Our studies revealed very interesting results. Comparison of radioactive elements level of some districts are found higher in some remote areas of Chhatarpur, Jhansi and Panna districts of this region. The higher values of Uranium in Indian have been reported in Himalayas of Himachal Pradesh by some researchers (Kaul et al; 1993). The effects were recorded everywhere but are well within the safe limits (200-600 $\mathrm{Bqm}^{-3}$ ) as recommended by the international commission on radiological protection (ICRP-93). However the Radon in many areas exceeded the recommended level. The radiation induced effects in the materials like glass, polymers and materials were studied using the heavy ion facilities from heavy ion accelerator in Germany. Presently, the heavy ion facilities are being used from nuclear science center, New Delhi (India). The irradiation facilities are available at BARC, Mumbai.

The following four Experimental Techniques were carried out for brief description:-

1. Estimation of Uranium: - Lexan polymer was used as a track recorder for recording fission tracks due to Uranium in the solid and liquid phase materials. The details of the technique are given by Fischer et al, 1975.

2. Indoor Radon studies:- Alpha sensitive plastic track detectors such as LR-115, CR-39, were generally employed in the bare mode (Alter and Fleischer, 1981) or Cup mode (Ram Chandran et al, 2003) for indoor Radon measurements in dwellings. The detector after exposure have to be etched and scanned for track density measurements, which is then converted to $\mathrm{Bqm}^{-3}$ using the calibration constant determined in laboratory. This technique has been used by many investigators in India and abroad for the measurement of Radon activities in dwellings.

3. Radium analysis:- Solid state nuclear track detectors were used for Radium analysis in solid phase materials such as soil, rocks and building materials using Alter and Price, 1972, Somagyi, 1990. Plastic track detectors may also be used.

4. Heavy ion irradiation studies:- The studies were carried out in different types of polymer, glasses and material using the beam facilities from the heavy ion accelerator with the help of BARC, Mumbai. The optical, chemical and spectroscopic studies were carried out in these detectors.

\section{ACKNOWLEDGEMENT:-}

The authors are thankful to Dr. S.K. Mishra, Senior Scientist, BARC Mumbai for his valuable help during entire work.

The authors are also grateful to Sri O.P. Paliwal, M/s M.D. Vijay Industries and Faridabad for his financial help.

\section{REFERENCES:-}

1. Alter, H.W. and Fleischer, R.L., 1981 Passive integrating radon monitor for environmental monitoring. Health phys., 40(5), 693.

2. Alter,H.W.and Price,P.B., 1972.Radon detection using track registration material, U.S.Patent,3,665,194 Terradex Corp.

3. Fleischer, R.L.; Price, P.B. and Walker,R.M.,1975.Nuclear tracks in Solids, Principles and Applications. University of California, Press, Berkeley, USA.

4. Henshaw DL, Eatough JP, Richardson RB, (1990). Radon as a causative factor in induction of myeloid leukaemia and other cancers. Lancet. $355: 1008$.

5. ICRP (1993). Protection against Radon-222 at home and at work. ICRP Publication 65, Annals of the ICRP, 23(2).

6. Kaul R, Umamaheshwar K, Chandrashekhar S, Deshmukh RD, Swarnkar BM.(1993). Uranium mineralization in the shiwaliks of North Western Himalaya, India. J.Geol. Soc. India. 41 : 243-258. 
7. Ramchandram, T.V.Eappen, K.P. Nair, R.N. Mayya, Y.S. and Sadasivan, S. (2003). Radon-thorn levels and inhalation dose distribution patterns in Indian dwellings. BARC 2003/E/026 report.pp. 124.

8. Seve J, Kunz E, Placek V. Lung cancer in Uranium miners and long term exposure to Radon daughter products. Health Phys. 1976; 30,433.

9. Somogyi, G., 1990. The environmental behaviour of Radium, Technical report series No. 310. International Atomic Energy Agency, Vienna. 1, 229-256.

10. UNSCEAR, 2000. United Nations Scientific Committee on the effects of atomic radiation. Exposures due to natural radiation sources, United Nations, New York. 